УДК 616.89:616-003.96:616-036.865-053.2

Для цитирования: Альбицкая Ж.В. Проблемы ранней инвалидности и социальной адаптации у детей с психическими расстройствами. Сибирский вестник психиатрии и наркологии. 2017; 4 (97): 57-61. https://doi.org/10.26617/1810-3111-2017-4(97)$57-61$

\title{
Проблемы ранней инвалидности и социальной адаптации у детей с психическими расстройствами
}

\section{Альбицкая Ж.В.}

Нижегородская государственная медииинская академия

Россия, 603005, Нижний Новгород, пл. Минина и Пожарского, д. 10/1

\section{PEЗЮME}

Данные официальной медицинской статистики последних десятилетий свидетельствуют о выраженной и стойкой тенденции роста психических расстройств в детском возрасте, высокие показатели детской заболеваемости превышают аналогичные показатели среди взрослого населения. Всё это обусловливает значительный рост инвалидизации детей, существенно ограничивает их жизнедеятельность и способствует утяжелению социальной адаптации и проблем интеграции детей в общество. Цель исследования - определение структуры инвалидности и возможностей социальной адаптации, анализ факторов, влияющих на раннее выявление психической патологии у детей с психическими расстройствами. Основные методы: клинико-психопатологический, клинико-катамнестический, статистический. Результаты. Обследовано 1886 пациентов с верифицированными диагнозами психических расстройств (по критериям МКБ-10): умственной отсталостью, ранним детским аутизмом и органическими психическими расстройствами. По результатам исследования проанализированы проблемы адекватной диагностики, причины несвоевременного оформления инвалидности. Выявлены факторы, приводящие к социальной дезадаптации и инвалидизации у детей с психическими расстройствами. Определены факторы, улучшающие социальную адаптацию у детей с психическими расстройствами: ранняя диагностика, дифференцированная и своевременная медикаментозная и психолого-педагогическая коррекция и выбор адекватного образовательного маршрута. К факторам, способствующим росту инвалидизирующих психических расстройств, относятся: выраженность интеллектуального дефекта, сложная структура дефекта, отсроченная диагностика, позднее начало комплексной коррекции и неадекватно выбранный профиль обучения.

Ключевые слова: детская инвалидность, социальная адаптация, дезадаптация, ранний детский аутизм, умственная отсталость, органические психические расстройства, профиль обучения, раннее вмешательство.

\section{ВВЕДЕНИЕ}

Данные официальной медицинской статистики последних десятилетий свидетельствуют о стойкой и значительной тенденции роста психических расстройств в детском возрасте в мире, а высокие показатели детской заболеваемости превышают аналогичные показатели среди взрослого населения $[2,3,7$, $9,15,16,18]$. В России, как и во всем мире, в последние десятилетия наблюдается неуклонный рост числа детей-инвалидов, что приобретает масштабный общенациональный характер. За период с 1999 по 2015 г. число детей-инвалидов (0-17 лет) по причине психической патологии увеличилось с 87329 до 130788 (на 49,8\%), а показатель инвалидности в расчете на 100 тыс. детского населения вырос с 255,8 до 461,2 (на 80,3\%) [2, 3, 7, 9, 10]. В общей структуре детской инвалидности психические расстройства вышли на первое место, составив $25,8 \%$, а в клинической структуре заболеваемости вырос процент детей-инвалидов вследствие расстройств аутистического спектра, органических психических расстройств, хронических неорганических психозов и умственной отсталости $[4,6,8]$. В клинической структуре повысился процент детей-инвалидов с ранним детским аутизмом (РДА), органическими психических расстройствами (ОПР), хроническими неорганическими психозами, детской шизофренией (ДШ), умеренной и тяжелой умственной отсталостью (УО) и депрессивными расстройствами $[2,3,10,11,12]$.
Значительный рост инвалидизации детей по причине психических расстройств в последнее десятилетие существенно ограничивает их жизнедеятельность и способствует развитию социальной дезадаптации, что приводит в будущем к трудностям в овладении навыками самообслуживания, общения, обучения и приобретения определенных профессиональных навыков, приводит к существенному ухудшению качества их жизни с тяжелыми социальноэкономическими последствиями как для семьи, так и для государства $[1,5,6,8,13,14,15,17]$.

Цель - определение структуры инвалидности и возможностей социальной адаптации, анализ факторов, влияющих на ранее выявление психической патологии у детей с психическими расстройствами.

\section{МАТЕРИАЛЫ И МЕТОДЫ}

Исследование проведено с 2010 по 2016 г. клиникопсихопатологическим и клинико-катамнестическим методами. Изучено 1886 медицинских карт детей в возрасте от рождения до 14 лет, состоящих на диспансерном учете у психиатра в связи с различными психическими расстройствами. За 426 детьми велось личное наблюдение. Общая выборка детей в исследовании была представлена пациентами с верифицированными диагнозами: умственная отсталость легкой степени ( $\mathrm{n}=327 / 17,3 \%)$, умственная отсталость умеренной и тяжелой степени $(\mathrm{n}=445 / 23,6 \%)$, ранний детский аутизм (n=518/27,5\%), органические психические расстройства $(\mathrm{n}=596 / 31,6 \%)$. 
Статистическая обработка результатов производилась при помощи пакетов «Stats» и «Fifer». Полученные данные анализировались путем сравнительного анализа таблиц сопряженности и определения критерия Пирсона $\left(\chi^{2}\right)$. Различия между сравниваемыми группами считались высоко статистически значимыми при р <0,001.

\section{РЕЗУЛЬТАТЫ И ОБСУЖДЕНИЕ}

Из общей выборки детей $(\mathrm{n}=1886 / 100 \%)$, включенных в исследование, инвалидность была оформлена 1116 пациентам.

В результате было выявлено, что чаще всего ( $<0,001)$ инвалидность получали дети, наблюдающиеся по поводу умеренной и тяжелой степени умственной отсталости и раннего детского аутизма; с более редкой частотой - пациенты, страдающие легкой умственной отсталостью и органическими психическими расстройствами (табл. 1).

Т а б ли ц а 1

Выборка пациентов с верифицированными диагнозами психического расстройства, относящимися к категории «ребенок-инвалид»

\begin{tabular}{|l|c|c|}
\hline \multicolumn{1}{|c|}{ Диагно3 } & \multicolumn{2}{|c|}{ Количество детей } \\
\cline { 2 - 3 } & Абс. & $\%$ \\
\hline $\begin{array}{l}\text { Умственная отсталость легкой степени } \\
\text { (F70) }\end{array}$ & 72 & $6,5 \%$ \\
\hline $\begin{array}{l}\text { Умственная отсталость умеренной } \\
\text { и тяжелой степени (F71-72) }\end{array}$ & $445^{*}$ & $39,9 \%$ \\
\hline $\begin{array}{l}\text { Органическое психическое расстройство } \\
\text { (F07) }\end{array}$ & 199 & $17,8 \%$ \\
\hline Ранний детский аутизм (F84) & $314^{*}$ & $28,1 \%$ \\
\hline
\end{tabular}

П р и м е ч а н и е. ${ }^{*}-\mathrm{p}<0,001$.

Отказ от оформления инвалидности чаще всего встречался среди пациентов, страдающих органическими психическими расстройствами и ранним детским аутизмом. При этом отказано в оформлении инвалидности детям с органическими психическими расстройствами в большинстве случаев по решению органов медико-социальной экспертизы. В то же время при раннем детском аутизме от оформления инвалидности чаще отказывались сами родители. Выявлено, что только 18,3\% (n=204) от общего количества детей, которым юридически и законодательно было положено оформление инвалидности, получили её в положенные сроки. С редкой частотой встречаемости ( $<0,001)$ инвалидность своевременно оформлялась больным с РДА - 121 ребенку из $518(23,3 \%)$. Отсроченная диагностика при этих расстройствах варьировала от 3 до 5 лет. Причинами несвоевременного оформления инвалидности при РДА также являлись позднее обращение к психиатру $(38,7 \%)$, неправильная диагностика и длительное наблюдение детей с расстройством, не дающим право на инвалидность, чаще всего с диагнозом задержка психического развития $(61,3 \%)$. Более чем в $30 \%$ $(\mathrm{n}=171)$ наблюдений, несмотря на правильно поставленный диагноз, врач не предлагал родителям оформить ребенку инвалидность в положенные сроки, а родители, в свою очередь, были не осведомлены о том, что имеют на это право.
Родители 433 детей (23\%) из общей выборки исследования длительное время отказывались от предложенной инвалидности, часто выражая несогласие с поставленным диагнозом. В то время как в $27 \%$ случаев $(\mathrm{n}=509)$ родители сами поднимали вопрос об оформлении инвалидности, однако им было отказано участковым психиатром в направлении для обращения в органы медико-социальной экспертизы.

Общеизвестно, что инвалидность является основным из критериев степени социальной адаптации, начиная с раннего детства. Основываясь на полученных значениях данного показателя, были определены наименее социально адаптированные группы детей с психическими расстройствами (табл. 2).

Т а б л и ц а 2

\begin{tabular}{|c|c|c|c|c|c|c|c|c|}
\hline \multicolumn{9}{|c|}{$\begin{array}{c}\text { Уровни социальной адаптации у детей } \\
\text { с психическими расстройствами (n=1886) }\end{array}$} \\
\hline \multirow{3}{*}{$\begin{array}{c}\text { Уровень } \\
\text { адаптации }\end{array}$} & \multicolumn{4}{|c|}{ Умственная отсталость } & \multirow{2}{*}{\multicolumn{2}{|c|}{$\begin{array}{c}\text { Органиче- } \\
\text { ское психи- } \\
\text { ческое рас- } \\
\text { стройство } \\
(\mathrm{n}=596)\end{array}$}} & \multirow{2}{*}{\multicolumn{2}{|c|}{$\begin{array}{c}\text { Ранний } \\
\text { детский } \\
\text { аутизм } \\
(\mathrm{n}=518)\end{array}$}} \\
\hline & \multicolumn{2}{|c|}{$\begin{array}{l}\text { легкой } \\
\text { степени } \\
(\mathrm{n}=327)\end{array}$} & \multicolumn{2}{|c|}{$\begin{array}{c}\text { умеренной/ } \\
\text { тяжелой сте- } \\
\text { пени }(\mathrm{n}=445)\end{array}$} & & & & \\
\hline & Абс & $\%$ & Абс & $\%$ & Абс & $\%$ & Абс & $\%$ \\
\hline Высокий & 0 & 0 & 0 & 0 & 0 & 0 & 0 & 0 \\
\hline Средний & $323^{*}$ & 17,1 & 0 & 0 & $326^{*}$ & 17,3 & 9 & 0,5 \\
\hline Низкий & 14 & 0,7 & 49 & 2,3 & $183^{*}$ & 9,7 & $187^{*}$ & 9,9 \\
\hline Дезадаптация & 0 & 0 & $396^{*}$ & 21 & 87 & 4,6 & $322^{*}$ & 17,1 \\
\hline
\end{tabular}

Пр и м е ч а н и е. $*-p<0,001$.

Наиболее социально адаптированными (средний уровень) из общей исследовательской выборки $(\mathrm{n}=1886)$ были дети с умственной отсталостью легкой степени $(\mathrm{n}=323 / 17,1 \%)$ и пациенты с органическими психическими расстройствами $(\mathrm{n}=326 / 17,3 \%)$, что соответствовало значимым показателям с высокой статистической достоверностью $(\mathrm{p}<0,001)$. Дезадаптация в большинстве случаев была зарегистрирована в группах детей с аутизмом $(n=322 / 17,1 \%)$ и умственной отсталостью умеренной и тяжелой степени $(\mathrm{n}=396 / 21 \%)$ в сравнении с другими детьми $(\mathrm{p}<0,001)$.

В группе детей с умственной отсталостью легкой степени ведущее значение для адаптации пациентов имели выраженность умственного недоразвития, правильно выбранный образовательный маршрут (коррекционная школа), установка на обучение трудовым навыкам и комплексная коррекция.

Для детей с умеренной и тяжелой умственной отсталостью более значимыми были тяжесть сопутствующих нарушений (сложная структура дефекта), а также правильно выбранный профиль обучения. Наиболее адаптированными оказались пациенты, обучавшиеся в коррекционной школе и проживающие дома, менее адаптированными - воспитанники специализированных интернатов и детских домов.

В группах детей с РДА для оценки социальной адаптации большое значение имели своевременная диагностика и раннее начало медико-психологопедагогической коррекции. 
Проведённый анализ клинического состояния и социальной адаптации больных показал, что значимую роль играли особенности определявшей клиническую картину психопатологической симптоматики: у грубо дезадаптированных больных преобладали негативные и кататонические симптомы, у остальных - фобические и психопатоподобные.

Для группы пациентов с органическими психическими расстройствами $(\mathrm{n}=596)$ в большинстве случаев $(\mathrm{p}<0,001)$ было характерно среднее овладение бытовыми навыками; в этой же группе низко адаптированных пациентов было выявлено 14,6\% детей $(\mathrm{n}=87)$. Обращает на себя внимание тот факт, что все инвалиды вследствие органических расстройств, которые получили среднее образование по коррекционной программе, были социально адаптированы. И напротив, дети, обучавшиеся при несоответствии профиля образования реальным возможностям (по программе массовой школы на индивидуальном или домашнем обучении) и недостаточной медико-психолого-педагогической коррекции, испытывали в дальнейшем серьезные проблемы в плане социализации и приобретения навыков. Bсе дети обнаруживали наибольшую несостоятельность в сфере общения, трудно овладевали навыками самообслуживания и простой бытовой жизни, а если и осваивали их, то фактически реализовывали только после стимуляции или многократного повторения. Умеренные и тяжёлые затруднения больные испытывали и в сфере межличностного взаимодействия и отношений в микросоциуме. Наибольшие трудности выявлены в когнитивной сфере и способностях к планированию и контролю повседневной деятельности.

Своевременное установление диагноза чрезвычайно важно не только для оформления инвалидности, но и выбора правильного профиля обучения. Вследствие недооценки тяжести умственного недоразвития при УО, РДА и ОПР, а также постановки более «легкого диагноза» дети не находились в системе коррекционного образования, что только ухудшало их социальную адаптацию. В группе больных РДА своевременное установление точного диагноза было важно для начала адекватной медикаментозной и психолого-педагогической коррекции. Общей проблемой образования для всех пациентов был перевод на надомную форму обучения, что приводило к их изоляции от сверстников и невозможности развития коммуникативных навыков.

Таким образом, несмотря на неблагоприятный прогноз детской инвалидности достижение приемлемого уровня социально-бытовой адаптации было возможно во всех четырех группах наблюдения при условии ранней и адекватной диагностики, своевременной медикаментозной и психологопедагогической коррекции, а также правильно выбранного соответствующего образовательного маршрута и обучения бытовым навыкам в школе и дома, приспосабливающим ребенка к самостоятельности и жизни интеграции его в общество.

\section{ВЫВОДЫ}

Инвалидность детства вследствие психических болезней в последние годы имеет тенденцию к увеличению среди всех групп психических расстройств детского возраста. Положительное влияние на последующую социальную адаптацию во всех группах пациентов оказывали своевременная и точная диагностика, ранняя медикаментозная и психологопедагогическая коррекция, правильно выбранный профиль учебного процесса и обучения бытовым навыкам в школе и дома. Наибольшее негативное влияние на последующую социальную адаптацию у инвалидов детства оказывали выраженность интеллектуального дефекта, сопутствующие нарушения и соматические расстройства (сложная структуpa дефекта), а также отсроченная диагностика, поздно начатая коррекция и неправильно выбранный профиль обучения.

\section{КОНФЛИКТ ИНТЕРЕСОВ}

Автор заявляет об отсутствии конфликта интересов в связи с публикацией данной статьи.

\section{ИСТОЧНИК ФИНАНСИРОВАНИЯ}

Автор заявляет об отсутствии финансирования при проведении исследования.

\section{СООТВЕТСТВИЕ ПРИНЦИПАМ ЭТИКИ}

Работа соответствует этическим стандартам Хельсинской декларации ВМА (протокол заседания Комитета по этике Нижегородской государственной медицинской академия № 14 от 07.11.2016).

\section{ЛИТЕРАТУРА}

1. Алексеева А.М., Ильина М.Н., Щелкова О.Ю. Социальнопсихологическая адаптация и особенности интеллектуального развития детей с различными формами дизонтогенеза. Вестник Южно-Уральского государственного университета. Серия: Психология. 2012; 31: 64-71.

2. Аутизм в России. Акция Социальный заказ «Статистика 2010-2011». http://www.autisminrussia.ru/html/action/actionstat-2010.htm\#pressreliz

3. Демчева Н.К., Король И.С. Клинико-динамические характеристики психических расстройств и качество жизни у инвалидов вследствие психических заболеваний. Российский психиатрический журнал. 2010; 2: 14-21.

4. Демчева Н.К. Проблемы инвалидности у детей с психическими расстройствами. Психическое здоровье детей страны - будущее здоровье нации: Сборник материалов Всероссийской конференции по детской психиатрии и наркологии (Ярославль, 2016 г.) / Под ред. Е.В. Макушкина. М.: 2016: $128-130$.

5. Корень Е.В., Куприянова Т.А. Концепция психического здоровья и психосоциальной реабилитации детей и подростков с психическими расстройствами. Журн. клинической и соичальной психиатрии. 2012; 3: 4-12.

6. Куприянова И.Е., Дашиева Б.А., Карауш И.С. Клиникопсихологические, биологические и социальные факторы риска развития психопатологических нарушений у детей с ограниченными возможностями здоровья. Сибирский вестник психиатрии и наркологии. 2012; 3 (72): 36-40.

7. Макушкин Е.В., Демчева Н.К., Творогова Н.А. Психическое здоровье детей и подростков в Российской Федерации в 2000-2012 гг. Обозрение психиатрии и медицинской психологии им. В.М. Бехтерева. 2013; 4: 10-19.

8. Макушкин Е.В., Демчева Н.К., Творогова Н.А. Психические расстройства в детском и подростковом возрасте у городских и сельских жителей Российской Федерации в 19912012 гг. (эпидемиологическое исследование). Журнал невропатологии и психиатрии им. С.С. Корсакова. 2014; 114 (2): 3-14. 
9. Макушкин Е.В., Жеребцова В.А. Приоритетные направления охраны здоровья ребенка в неврологии и психиатрии (диагностика, терапия, реабилитация и профилактика). Итоги научно-практической конференции. Вестник новых медииинских технологий. 2011; 4 (18): 291-293.

10. Михейкина О.В. Эпидемиология умственной отсталости (обзор литературы). Обозрение психиатрии и медицинской психологии им. В.М. Бехтерева. 2012; 3: 24-33.

11. Семке В.Я., Куприянова И.Е., Дашиева Б.А. Психическое здоровье школьников: транскультуральный аспект. Томск, 2006: 162.

12. Чуркин А.А., Демчева Н.К., Ходырева Е.А. Показатели заболеваемости умственной отсталостью среди детей и подростков населения Российской Федерации в 1999-2012 гг. Вестник неврологии, психиатрии и нейрохирургии. 2012; 9: 4-11.

13. Bugie C. Child development and early intervention centers. Rev Neurol. 2013; 34 (1): 143-148.
14. Bridgens R. Disability and Being «Normal»: A Response to McLaughlin and Godley. Sociology. 2009; 43: 753-761.

15. Einfeld S.L., Piccinin A.M., Mackinnon A., et al. Psychopathology in young people with intellectual disability. JAMA. 2011; 296 (16): 1981-1989.

16. Garralda M.E., Raynaud J.P. Brain, mind, and developmental psychopathology in childhood. International Association of Child and Adolescent Psychiatry and Allied Professions (IACAPAP). 2012: 317.

17. Kovac M. Some specificities of rehabilitation of children with special needs. Med Pregl. 2012; 58 (9-10): 483-485.

18. Thurgate C., Warner H. Living with disability: part 1. J Paediatr Nurs. 2013; 17 (10): 37-44.

Поступила в редакщию 24.09.2017 Утверждена к печати 30.10.2017

Альбицкая Жанна Вадимовна, к.м.н., доцент кафедры психиатрии и медицинской психологии.

Альбицкая Жанна Вадимовна, zhanna051267@gmail.com

УДК 616.89:616-003.96:616-036.865-053.2

For citation: Albitskaya Zh.V. The problem of early disability and social adaptation in children with various mental disorders. Siberian Herald of Psychiatry and Addiction Psychiatry. 2017; 4 (97): 57-61. https://doi.org/10.26617/1810-3111-2017-4(97)-5761

\section{The problem of early disability and social adaptation in children with various mental disorders}

\section{Albitskaya Zh.V.}

Nizhny Novgorod State Medical Academy

Minin and Pozharsky Square 10/1, 603005, Nizhniy Novgorod, Russian Federation

\section{ABSTRACT}

Data from official medical statistics of the last decades indicate a pronounced and consistent trend of increase in mental disorders among children and high rates of child morbidity higher than among the adult population. All this leads to a significant increase of child disability that significantly limits their activity and contributes to the enhancement of social adaptation and problems of integration of children into society. The aim of the study was to determine the structure of disability, opportunities for social adaptation and analysis of the factors influencing early detection of mental health problems in children with various mental disorders. Methods: clinical-psychopathological, clinical-catamnestical, statistical. 1886 patients with verified diagnoses of mental disorders (according to ICD-10 criteria): mental retardation, infantile autism and organic mental disorders were examined. The study analyzed the problems of adequate diagnosis, untimely registration of disability and the factors leading to social exclusion and disability in the groups of children with various mental disorders. Factors that enhance social adaptation in children with mental disorders were as follows: early detection, differentiated and timely medical and psycho-pedagogical correction and selection of appropriate educational route. The factors contributing to the growth and debilitating the mental disorders include: severity of the intellectual defect, structure of defect, delayed diagnosis, late start of complex correction and inadequately selected educational profile.

Keywords: child disability, social adaptation, disadaptation, early infantile autism, mental retardation, organic mental disorders, educational profile, early intervention.

\section{REFERENCES}

1. Alekseeva A.M., Ilina M.N., Schelkova O.Yu. Sotsialnopsihologicheskaya adaptatsiya i osobennosti intellektualnogo razvitiya detey s razlichnyimi formami dizontogeneza [Sociopsychological adaptation and intellectual development peculiarities of children with various forms of dysontogenesis]. Vestnik Yuzhno-Uralskogo gosudarstvennogo universiteta. Seriya: Psihologiya - Bulletin of South-Urals State University. Series: Psychology. 2012; 31: 64-71 (in Russian).

2. Autizm v Rossii. Aktsiya Sotsialnyiy zakaz «Statistika 20102011». http://www.autisminrussia.ru/html/action/action-stat2010.htm\#pressreliz (in Russian).

3. Demcheva N.K., Korol I.S. Kliniko-dinamicheskie harakteristiki psihicheskih rasstroystv i kachestvo zhizni u invalidov vsledstvie psihicheskih zabolevaniy [Clinical-dynamic characteristics of mental disorders and quality of life in disabled people due to mental diseases]. Rossiyskiy psihiatricheskiy zhurnal - Russian Journal of Psychiatry. 2010; 2: 14-21 (in Russian).

4. Demcheva N.K. Problemyi invalidnosti u detey s psihicheskimi rasstroystvami. Psihicheskoe zdorove detey stranyi - buduschee zdorove natsii [Problems of disability in children with mental disorders. Mental health of children of the country - future health of the nation]: Sbornik materialov Vserossiyskoy konferentsii po detskoy psihiatrii i narkologii (Yaroslavl, 2016 g.). E.V. Makushkin, ed. M.: 2016: 128-130 (in Russian).

5. Koren E.V., Kupriyanova T.A. Kontseptsiya psihicheskogo zdorovya i psihosotsialnoy reabilitatsii detey i podrostkov $\mathrm{s}$ psihicheskimi rasstroystvami [Concept of mental health an psychosocial rehabilitation of children and adolescents with mental disorders]. Zhurnal klinicheskoy $i$ sotsialnoy psihiatrii - Journal of Clinical and Social Psychiatry. 2012; 3: 4-12 (in Russian). 
6. Kupriyanova I.E., Dashieva B.A., Karaush I.S. Klinikopsihologicheskie, biologicheskie i sotsialnyie faktoryi riska razvitiya psihopatologicheskih narusheniy u detey s ogranichennyimi vozmozhnostyami zdorovya [Clinical-psychological, biological and social risk factors of development of psychopathological disturbances in children with disabilities]. Sibirskiy vestnik psihiatrii $i$ narkologii - Siberian Herald of Psychiatry and Addiction Psychiatry. 2012; 3 (72): 36-40 (in Russian).

7. Makushkin E.V., Demcheva N.K., Tvorogova N.A. Psihicheskoe zdorove detey i podrostkov v Rossiyskoy Federatsii v 2000-2012 gg [Mental health of children and teenagers in the russian federation in 2000-2012]. Obozrenie psihiatrii $i$ meditsinskoy psihologii im. V.M. Behtereva - V.M. Bekhterev Review of Psychiatry and Medical Psychology. 2013; 4: 10-19 (in Russian) (in Russian).

8. Makushkin E.V., Demcheva N.K., Tvorogova N.A. Psihicheskie rasstroystva $\mathrm{v}$ detskom i podrostkovom vozraste u gorodskih $\mathrm{i}$ selskih zhiteley Rossiyskoy Federatsii v 1991-2012 gg. (epidemiologicheskoe issledovanie) [Mental disorders in children and adolescents from urban and rural areas of the Russian Federation in 1991-2012 (an epidemiological study)]. Zhurnal nevrologii $i$ psihiatrii im. S.S. Korsakova - S.S. Korsakov Journal of Neurology and Psychiatry. 2014; 114 (2): 3-14 (in Russian).

9. Makushkin E.V., Zherebtsova V.A. Prioritetnyie napravleniya ohranyi zdorovya rebenka v nevrologii i psihiatrii (diagnostika, terapiya, reabilitatsiya i profilaktika). Itogi nauchno-prakticheskoy konferentsii [Change of microcirculations vessels in various departments of heart at action sublimited physical activities]. Vestnik novyih meditsinskih tehnologiy - Bulletin of New Medical Technologies. 2011; 4 (18): 291-293 (in Russian).

10. Miheykina O.V. Epidemiologiya umstvennoy otstalosti (obzor literaturyi) [Epidemiology of Mental Retardation (a literature review)]. Obozrenie psihiatrii i meditsinskoy psihologii im. V.M.
Behtereva - V.M. Bekhterev Review of Psychiatry and Medical Psychology. 2012; 3: 24-33 (in Russian).

11. Semke V.Ya., Kupriyanova I.E., Dashieva B.A. Psihicheskoe zdorove shkolnikov: transkulturalnyiy aspect [Mental health of schoolchildren: transcultural aspect]. Tomsk, 2006: 162 (in Russian).

12. Churkin A.A., Demcheva N.K., Hodyireva E.A. Pokazateli zabolevaemosti umstvennoy otstalostyu sredi detey i podrostkov naseleniya Rossiyskoy Federatsii v 1999-2012 gg [Indices of sickness rate with mental retardation among children and adolescents of the population of the Russian Federation in 19992012]. Vestnik nevrologii, psihiatrii i neyrohirurgii - Bulletin of Neurology, Psychiatry and Neurosurgery. 2012; 9: 4-11 (in Russian).

13. Bugie C. Child development and early intervention centers. Rev Neurol. 2013; 34 (1): 143-148.

14. Bridgens R. Disability and Being «Normal»: A Response to McLaughlin and Godley. Sociology. 2009; 43: 753-761.

15. Einfeld S.L., Piccinin A.M., Mackinnon A., et al. Psychopathology in young people with intellectual disability. JAMA. 2011; 296 (16): 1981-1989.

16. Garralda M.E., Raynaud J.P. Brain, mind, and developmental psychopathology in childhood. International Association of Child and Adolescent Psychiatry and Allied Professions (IACAPAP). 2012: 317.

17. Kovac M. Some specificities of rehabilitation of children with special needs. Med Pregl. 2012; 58 (9-10): 483-485.

18. Thurgate C., Warner H. Living with disability: part 1. J Paediatr Nurs. 2013; 17 (10): 37-44.

Received September 24.2017 Accepted October 30.2017

Albitskaya Zhanna V., MD, senior lecturer of Psychiatry and Medical Psychology Department, Nizhny Novgorod State Medical Academy, Nizhniy Novgorod, Russian Federation.

Albitskaya Zhanna V., zhanna051267@gmail.com 